\title{
DNA-PK promotes the survival of young neurons in the embryonic mouse retina
}

\author{
J Baleriola ${ }^{1}$, T Suárez ${ }^{1}$ and EJ de la Rosa ${ }^{\star, 1}$
}

Programmed cell death is a crucial process in neural development that affects mature neurons and glial cells, as well as proliferating precursors and recently born neurons at earlier stages. However, the regulation of the early phase of neural cell death and its function remain relatively poorly understood. In mouse models defective in homologous recombination or nonhomologous end-joining (NHEJ), which are both DNA double-strand break (DSB) repair pathways, there is massive cell death during neural development, even leading to embryonic lethality. These observations suggest that natural DSBs occur frequently in the developing nervous system. In this study, we have found that several components of DSB repair pathways are activated in the developing mouse retina at stages that coincide with the onset of neurogenesis. In short-term organotypic retinal cultures, we confirmed that the repair pathways can be modulated pharmacologically. Indeed, inhibiting the DNA-dependent protein kinase (DNA-PK) catalytic subunit, which is involved in NHEJ, with NU7026 increased caspase-dependent cell death and selectively reduced the neuron population. This observation concurs with an increase in the number of apoptotic neurons found after NU7026 treatment, as also observed in the embryonic scid mouse retina, a mutant that lacks DNA-PK catalytic subunit activity. Therefore, our results implicate the generation of DSB and DNA-PK-mediated repair in neurogenesis in the developing retina.

Cell Death and Differentiation (2010) 17, 1697-1706; doi:10.1038/cdd.2010.46; published online 7 May 2010

During neural development, programmed cell death occurs from the early stages of proliferation until the later stages of functional maturation, constituting a part of the process that generates the sophisticated cytoarchitecture and connectivity of the nervous system. Although the early phase of cell death affecting proliferating neuroepithelial cells and recently born neurons has been recognized, how it is regulated and its function have only partially been characterized. ${ }^{1-3}$ The relevance of early neural cell death has become evident in genetically modified mice, which also provide some clues as to the elements that control its regulation and function. ${ }^{1-4}$ Besides the strong reduction in cell death found in knockout mice deficient in executor and regulatory proapoptotic genes, a dramatic increase in neural cell death has been observed in animals with deficient double-strand break (DSB) repair. As most other tissues are only weakly affected, or are not affected at all, it seems that DSBs are selectively generated during neural development and underlie the early phase of cell death occurring in this tissue..$^{2,5-10}$

DSBs, the most deleterious kind of alteration to DNA, are produced by endogenous or exogenous agents. During normal embryonic development, DSBs are likely to be a consequence of endogenous cellular activity and may be caused by replication stress during proliferation, transcriptional activity or oxidative stress produced by normal metabolism. ${ }^{11,12}$ In addition, DSBs can be programmed to generate diversity in the immune system. ${ }^{13}$ In eukaryotes, DSBs are repaired by either homologous recombination (HR) or nonhomologous end-joining (NHEJ). HR repairs DSBs without altering the DNA sequence, using a sister chromatid as an undamaged template. Conversely, NHEJ involves the direct ligation of the two DNA ends without ensuring that the correct sequence is restored. Thus, although $\mathrm{HR}$ is functionally important in the cell cycle phases from synthesis to mitosis, NHEJ participates in repair throughout the cell cycle and in postmitotic cells. Although NHEJ is an error-prone repair process, it is considered to be the predominant pathway in mammals. ${ }^{7,12}$

DSBs trigger a signaling cascade that leads to the rapid formation of a repair focus at the break. One of the earliest events in DNA damage response is the Ser139 phosphorylation of histone $\mathrm{H} 2 \mathrm{AX}(\gamma \mathrm{H} 2 \mathrm{AX})$ by members of the phosphatidylinositol-3 kinase-like family, such as ataxia telangiectasia and Rad-3 related (ATR), ataxia telangiectasia mutated (ATM) and DNA-dependent protein kinase (DNA-PK). ${ }^{14}$ The presence of these activated proteins in foci implies a preexisting DSB. Although these kinases share downstream substrates and cooperate under certain conditions, they have nonredundant functions. ${ }^{12,14,15}$ Both ATR and ATM are checkpoint kinases that coordinate cell cycle progression

\footnotetext{
${ }^{1} 3 \mathrm{D}$ Lab (Development, Differentiation \& Degeneration), Department of Cellular and Molecular Medicine, Centro de Investigaciones Biológicas, Consejo Superior de Investigaciones Científicas, Madrid, Spain

${ }^{*}$ Corresponding author: EJ de la Rosa, 3D Lab (Development, Differentiation \& Degeneration), Department of Cellular and Molecular Medicine, Centro de Investigaciones Biológicas, Ramiro de Maetzu 9, Consejo Superior de Investigaciones Científicas, Madrid E-28040, Spain. Tel: + 34918373112 , Ext 4375; Fax: + 3491536 0432; E-mail: ejdelarosa@ cib.csic.es

Keywords: double-strand break; DNA repair; NHEJ; apoptosis; programmed cell death; neuronal differentiation

Abbreviations: ATM, ataxia telangiectasia mutated; ATR, ataxia telangiectasia and Rad-3 related; DNA-PK, DNA-dependent protein kinase; DSB, double-strand break; E, embryonic day; $\gamma \mathrm{H} 2 \mathrm{AX}$, Ser139 phosphorylated histone H2AX; HR, homologous recombination; NHEJ, nonhomologous end-joining; P, postnatal day; RGC, retinal ganglion cell; RT, room temperature; SCID, severe combined immunodeficiency; TUNEL, TdT-mediated dUTP nick end-labeling

Received 07.9.09; revised 15.3.10; accepted 01.4.10; Edited by P Salomoni; published online 07.5.10
} 
after DNA damage. Whereas ATR is activated by singlestranded overhangs generated at DSBs or single-stranded DNA originated from stalled replication forks during the $S$ phase, ATM responds to DSBs ${ }^{15,16}$ and it has been implicated in the NHEJ repair pathway. ${ }^{17}$ DNA-PK is a protein complex required for efficient NHEJ, which includes Ku70, Ku80 and the DNA-PK catalytic subunit . 7,13

The neuroretina is a classic model system to study basic cellular processes involved in neural development, including cell death. ${ }^{18,19}$ Retinas can be grown ex vivo in organotypic cultures with chemically defined medium, in which proliferation, differentiation and cell death follow a developmental course similar to that seen in vivo. ${ }^{20-22}$ Short-term pharmacological manipulations can be used in these organotypic cultures to define the relationship and hierarchy between ongoing processes, which is not always possible in genetically manipulated animals because of the activation of compensatory events. We have inhibited ATM or DNA-PK activity in organotypic cultures of the mouse neuroretina at embryonic day $(E) 14.5$ to define the populations affected by DSBs and to characterize the selective contribution of DNA repair pathways to retinal development. Remarkably, diminished DNAPK activity resulted in selective death of recently born neurons, an observation corroborated in the embryonic retina of scid mice, thereby supporting a selective role for NHEJ in early retinal neurogenesis.

\section{Results}

Divergent patterns of cell death and H2AX activation in the developing mouse retina. To characterize the relationships between the generation and repair of DSBs, programmed cell death and neuronal differentiation, we studied several developmental stages between E13.5, when the generation of retinal ganglion cells (RGCs) commenced, and postnatal day $(P) 2$, when a prominent phase of neurotrophic cell death affects RGCs (see Cepko et al. ${ }^{18}$ and Valenciano et al. ${ }^{19}$ for details). The presence of DSBs was determined by $\gamma \mathrm{H} 2 \mathrm{AX}$ immunostaining, whereas TdT-mediated dUTP nick end-labeling (TUNEL) was used to visualize cell death (Figure 1). Cells undergoing each of these processes were evident in freshly dissected, wholemount retinas at all ages studied (Figure $1 \mathrm{~g}$ ), although the relative number of cells undergoing each process did not evolve in parallel. Although the density of TUNEL-positive
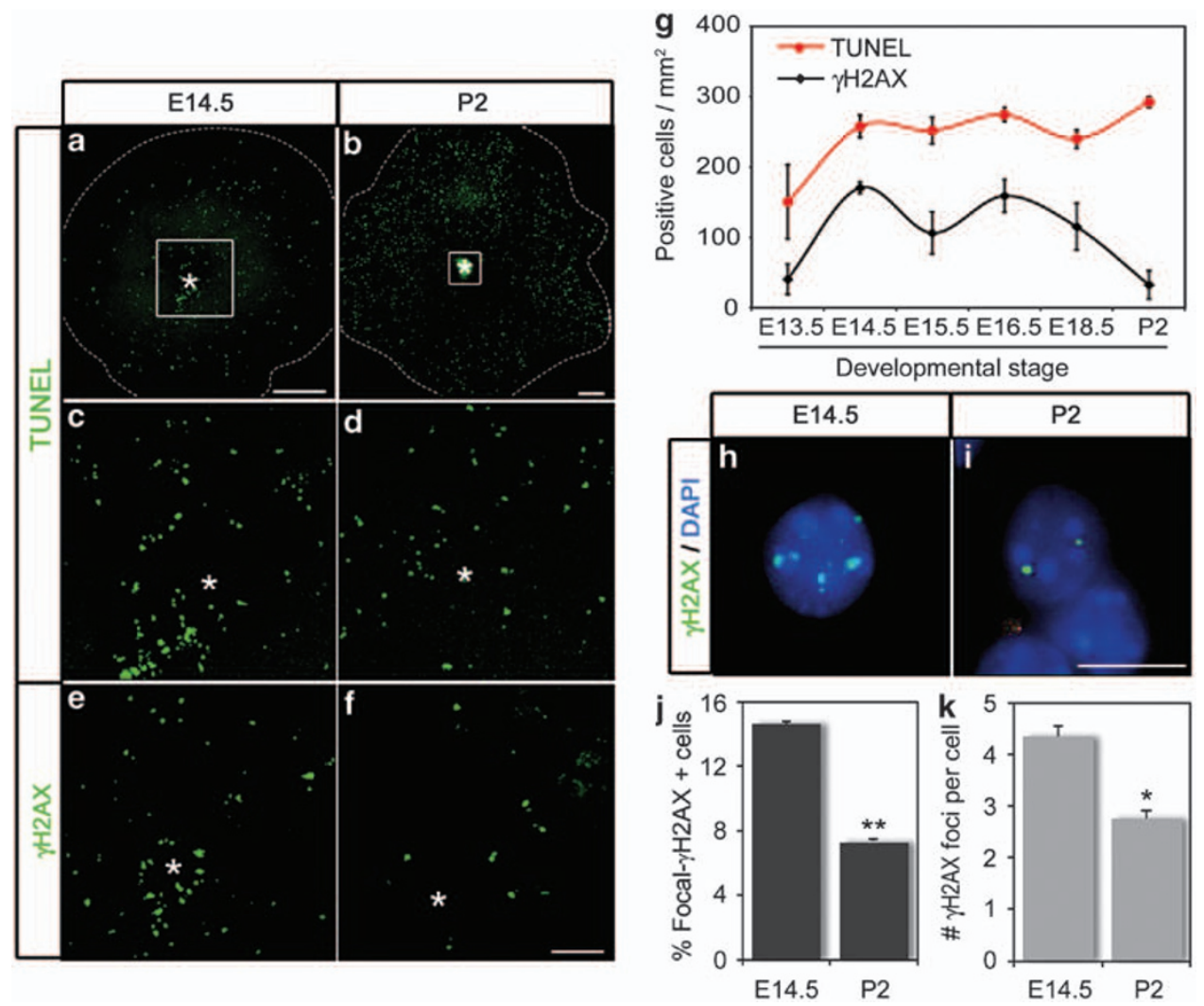

Figure 1 Patterns of naturally occurring cell death and $\mathrm{H} 2 \mathrm{AX}$ phosphorylation in the developing mouse retina. Embryonic and postnatal retinas at the indicated ages were flat mounted and processed for TUNEL ( $\mathbf{a}-\mathbf{d}$ and red line in $\mathbf{g}$ ) or for $\gamma \mathrm{H} 2 \mathrm{AX}$ immunostaining (e, $\mathbf{f}$ and black line in $\mathbf{g}$ ). Dotted lines ( $\mathbf{a}$ and $\mathbf{b}$ ) indicate the borders of the retina and boxes ( $\mathbf{a}$ and $\mathbf{b}$ ) indicate the areas shown at a higher magnification in $\mathbf{c}$ and $\mathbf{e}$, and in $\mathbf{d}$ and $\mathbf{f}$, respectively. Asteriks ( $\mathbf{a}-\mathbf{f})$ indicate the optic nerve head. The image in $\mathbf{b}$ is a reconstruction of five confocal microscopy fields of a P2 retina. TUNEL-positive apoptotic bodies and $\gamma \mathrm{H} 2 \mathrm{AX}$-positive cells were scored in the whole retina and normalized by area. The graph $(\mathbf{g})$ illustrates the mean \pm S.E.M. of at least four individual retinas per age. Focal distribution of $\gamma \mathrm{H} 2 \mathrm{AX}(\mathbf{h}$ and $\mathbf{i}$ ) is shown in immunostained dissociated cells. Graphs ( $j$ and $\mathbf{k}$ ) represent the mean \pm S.E.M. of the proportion of cells showing a focal nuclear distribution for $\gamma \mathrm{H} 2 \mathrm{AX}(\mathrm{j})$ or the number of foci per cell (k) in E14.5 versus $\mathrm{P} 2$ retinas found in four preparations (a minimum of 100 cells were scored). ${ }^{*} P<0.05,{ }^{*} P<0.01$, with respect to the E14.5 values. Scale bar, $300 \mu \mathrm{m}$ in a and $\mathbf{b}$; $40 \mu \mathrm{m}$ in $\mathbf{c}-\mathbf{f}$; $10 \mu \mathrm{m}$ in $\mathbf{h}$ and $\mathbf{i}$ 
cells was similar between E14.5 and P2, the density of $\gamma \mathrm{H} 2 \mathrm{AX}$ diminished after $\mathrm{E} 16.5$ and reached a minimum at P2 (Figures $1 \mathrm{a}-\mathrm{g}$ ). To corroborate the differential activation of $\mathrm{H} 2 \mathrm{AX}$ between E14.5 and P2, freshly dissected retinas from both ages were dissociated into single cell suspensions and processed for $\gamma \mathrm{H} 2 \mathrm{AX}$ immunostaining to reveal discrete nuclear foci, a landmark of activated DSB repair (Figures $1 \mathrm{~h}-\mathrm{k}$ ). In close correlation with the observations from whole-mount retinas, H2AX phosphorylation was greater at E14.5 than at P2 by considering both the percentage of cells with nuclear foci and the number of foci per cell. This observation confirmed that DSBs are more abundant at early stages of retinal development. The differential activation of $\mathrm{H} 2 \mathrm{AX}$ was not accompanied by fluctuations in H2AX mRNA or in the expression of other molecules that respond to DNA damage (Supplementary Figure 1). Thus, unlike other model systems, ${ }^{23} \mathrm{H} 2 \mathrm{AX}$ activation during retinal development does not seem to be linked to apoptotic DNA cleavage but, rather, to some other process occurring selectively at early developmental stages.

In light of these results, we focused on E14.5 retinas when $\gamma \mathrm{H} 2 \mathrm{AX}$ and TUNEL quantifications were more similar than at later stages, and when both DSB repair and cell death coexist with neuron generation, particularly that of RGCs. To establish a possible association between H2AX activation and cell death, we first compared the patterns of staining in
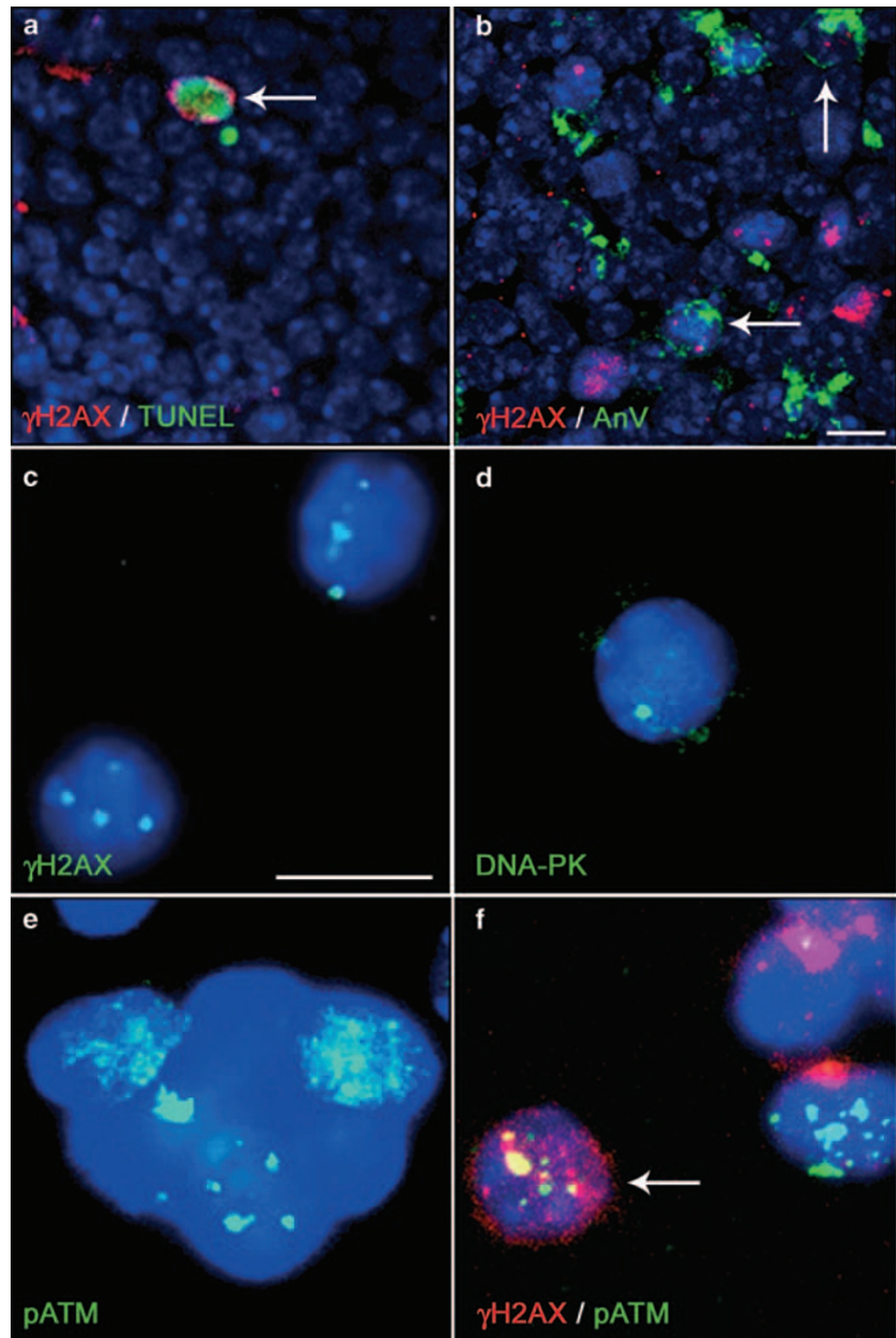

Figure 2 DSBs, their active repair and programmed cell death, coexist in the E14.5 retina. Freshly dissected E14.5 retinas were flat mounted and costained for $\gamma \mathrm{H} 2 \mathrm{AX}$ and for the apoptotic markers TUNEL (a) or Annexin V (b). Double-stained cells are indicated with an arrow. The focal nuclear distribution of $\gamma \mathrm{H} 2 \mathrm{AX}$ (c and f), DNA-PK (d) and pATM (e and f) was visualized in retinal dissociated cells. Scale bar, $10 \mu \mathrm{m}$ 
whole-mount retinas. Markers for both these processes were occasionally present in the same cell (Figures $2 a$ and b). Although $\gamma \mathrm{H} 2 \mathrm{AX}$ colocalized with TUNEL, it more frequently colocalized with Anexin-V staining (three- to fourfold, data not shown), an earlier marker of programmed cell death than TUNEL. This preferential association of $\gamma \mathrm{H} 2 \mathrm{AX}$ with an early marker of apoptosis again indicated that $\mathrm{H} 2 \mathrm{AX}$ activation is not a consequence of the apoptotic DNA cleavage revealed by TUNEL, at least during retinal development. In addition to $\gamma \mathrm{H} 2 \mathrm{AX}$, additional landmarks of active DSB repair were found in discrete nuclear foci, namely, Ser1981 phosphorylated ATM and DNA-PK, with some overlap in the distribution of pATM and $\gamma \mathrm{H} 2 \mathrm{AX}$ (Figures $2 \mathrm{c}-\mathrm{f}$ ). Thus, the DSB repair machinery seems to be intrinsically active in the developing mouse retina.

DSB repair pathways can be modulated in E14.5 retinas ex vivo. Next, we established an experimental design to induce the activation of DSB DNA repair in the embryonic retina and to experimentally manipulate this process. The topoisomerase II inhibitor etoposide provokes DSBs, as well as the rapid activation of ATM, ATR, DNA-PK and their corresponding substrates. ${ }^{24-26}$ Exposing E14.5 retinas to etoposide in organotypic culture increased the accumulation of $\gamma \mathrm{H} 2 \mathrm{AX}$ and total p53 (Figure 3a), two common substrates of ATM, ATR and DNA-PK, ${ }^{13,14,16}$ and indicative of the response of retinal cells to a genotoxic agent. Chk1, which is primarily activated by ATR, ${ }^{16,27}$ also seemed to be phosphorylated in etoposide-treated retinas. Further, the levels of p21, a protein that regulates cell cycle progression after DNA damage in a p53-dependent manner, ${ }^{16,28}$ were found increased after etoposide treatment (Figure 3a). At the cellular level, etoposide induced the appearance of a large number of $\gamma \mathrm{H} 2 \mathrm{AX}$ nuclear foci after $30 \mathrm{~min}$. These foci progressively disappeared over a 150-min period after the removal of etoposide, before the appearance of apoptotic cells in tissues (Figures $3 b-f$ and data not shown). These results indicate that the developing retina could modulate the activation of the repair process in response to DNA damage.
Inhibition of DNA-PK ex vivo and its deficiency in vivo result in increased cell death in the E14.5 retina. In light of our observation in vivo during retinal development, we focused on the NHEJ repair pathway, which is the only process capable of functioning on young, postmitotic neurons that are actively generated at E14.5. DNA-PK is an essential component of this pathway and it can be inhibited by NU7026. E14.5 retinas cultured in the presence of NU7026 had reduced levels of $\gamma \mathrm{H} 2 \mathrm{AX}$ and total p53, but not of pAkt, an important survival mediator that is also a downstream substrate of phosphatidylinositol-3 kinase activity (Figures $4 \mathrm{a}$ and $\mathrm{b}$ ). In etoposide-treated retinas, the selectivity of NU7026 treatment was compared with that of KU55933, an inhibitor of ATM. KU55933 reduced etoposidemediated increase of p21, a downstream substrate of ATM, but not of pChk1, primarily activated by the related ATR kinase. Conversely, DNA-PK inhibition did not affect either of these substrates ${ }^{16,27,28}$ (Figure 4c).

Having confirmed the selective inhibitory effects of NU7026 and KU55933, we studied the cellular consequences of interfering with the intrinsic activity of DNA-PK. It should be noted that in these experiments, no treatment was used to exogenously induce DSBs and the repair pathways (i.e., UV irradiation or genotoxic agents), and the ATM inhibitor KU55933 was used as a control in selected experiments to better define the processes selectively dependent on DNA-PK. There was a significant increase in the density of TUNELpositive nuclei in cultured E14.5 retinas after as little as $6 \mathrm{~h}$ in the presence of NU7026 (Figures 5a-d), whereas KU55933 did not induce cell death under similar conditions. As shown above (Figures $4 a$ and b), NU7026 did not affect Akt phosphorylation at the concentrations used, indicating that its effect on cell survival was not due to nonspecific inhibition of the phosphatidylinositol-3 kinase-Akt survival pathway. To strengthen our observations, we analyzed the retinal phenotype of a mouse model with severe combined immunodeficiency (SCID) that expresses a truncated, enzymatically inactive form of the DNA-PK catalytic subunit . ${ }^{29}$ Although no differences were found in E14.5 retinas in the proportion of
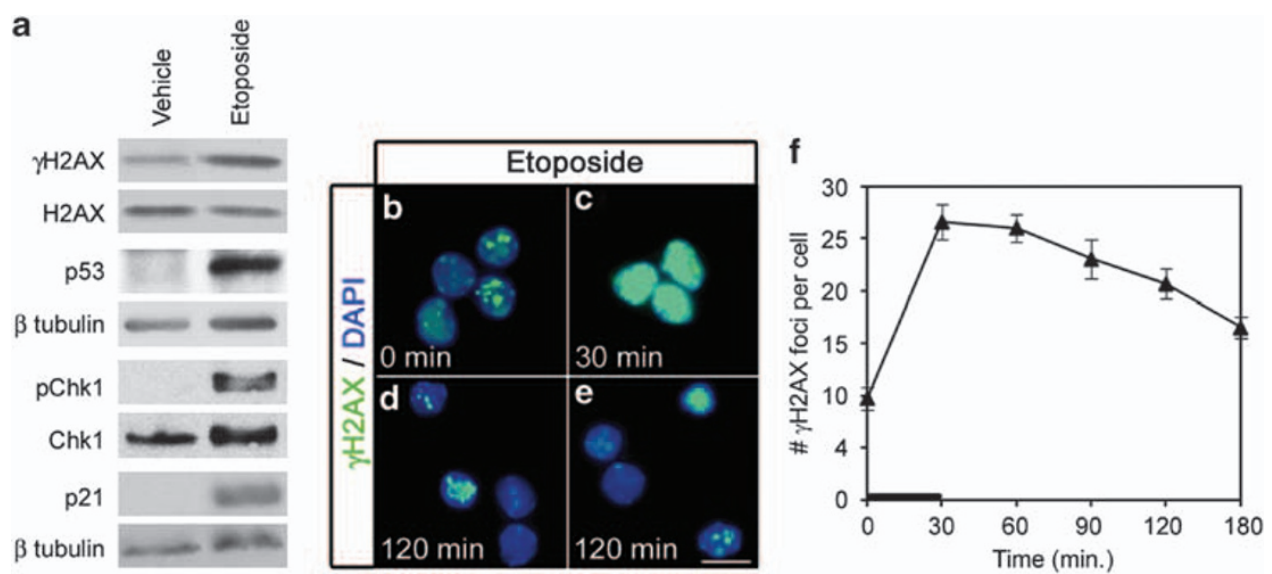

Figure 3 Induction of the DNA damage response in organotypic retinal cultures. E14.5 retinas were cultured for $6 \mathrm{~h}$ in the presence of etoposide (a), or for $30 \mathrm{~min}$, followed by $2.5 \mathrm{~h}$ incubation without the drug $(\mathbf{b}-\mathbf{f})$. The levels of $\gamma \mathrm{H} 2 \mathrm{AX}, \mathrm{H} 2 \mathrm{AX}, \mathrm{p} 53$, pChk1, Chk1, p21 and $\beta$ tubulin were analyzed in western blots of total protein extracts (a). Cultured retinas were dissociated into single cell suspension and immunostained for $\gamma \mathrm{H} 2 \mathrm{AX}$ to analyze the dynamics of appearance and disappearance of nuclear foci $(b-e$ and $\mathbf{f})$. The graph (f) represents the mean \pm S.E.M. of the number of foci found in 80 cells per time. The solid black line in $f$ indicates the exposure time to etoposide. Scale bar, $10 \mu \mathrm{m}$ 


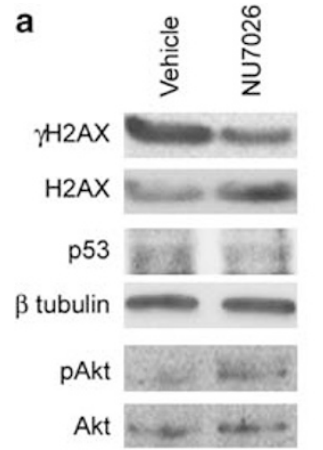

b

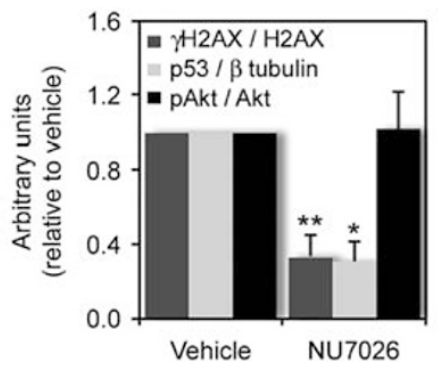

C

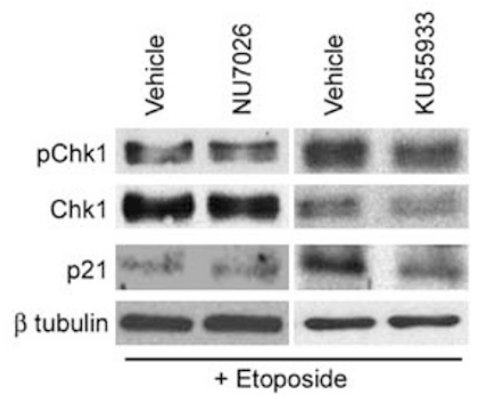

Figure 4 Inhibition of DSB repair pathways in organotypic retinal cultures. E14.5 retinas were cultured for $6 \mathrm{~h}$ in the presence of the indicated compounds. The levels of $\gamma \mathrm{H} 2 \mathrm{AX}, \mathrm{H} 2 \mathrm{AX}, \mathrm{p} 53, \mathrm{pAkt}, \mathrm{Akt}$ and $\beta$ tubulin in basal conditions (a) or of pChk1, Chk1, p21 and $\beta$ tubulin in etoposide-treated retinas (c) were analyzed by western blots of total protein extracts. The graph $(\mathbf{b})$ shows the quantification of western blots in basal conditions and illustrates the mean \pm S.E.M. of at least three independent experiments. ${ }^{\star} P<0.05, * * P<0.01$, with respect to vehicle
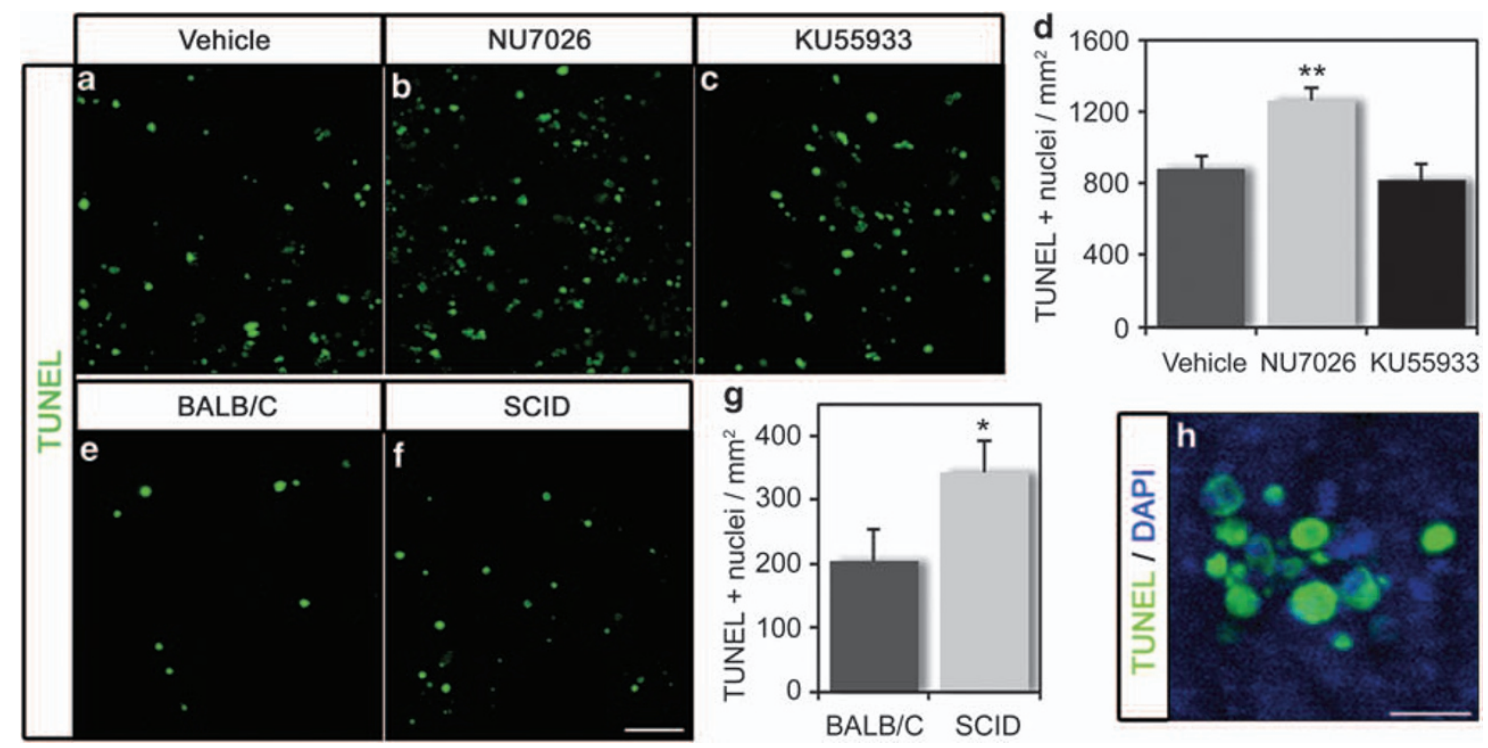

Figure 5 Effect of DNA-PK inhibition on cell survival ex vivo and in vivo. E14.5 retinas cultured with the indicated compounds for $6 \mathrm{~h}$ (a-d) or freshly dissected E14.5 retinas from wild type $(B A L B / c)$ and scid embryos $(\mathbf{e}-\mathbf{g})$ were flat mounted and processed for TUNEL. TUNEL-positive apoptotic nuclei were scored in the whole retina and normalized per area. The graphs illustrate the mean \pm S.E.M. of at least five individual retinas cultured in three independent experiments (d) or of four individual retinas dissected from embryos with the indicated genotypes $(\mathbf{g})$. Panel $\mathbf{h}$ shows a higher magnification detail of the typical TUNEL staining in cells undergoing apoptotic nuclear fragmentation (green) and the corresponding nuclear counterstain with DAPI (blue). ${ }^{\star} P<0.05,{ }^{\star \star} P<0.01$, with respect to the corresponding controls. Scale bar, $40 \mu \mathrm{M}$ in a-c, e and $\mathbf{f}$, and $10 \mu \mathrm{M}$ in $\mathbf{h}$

total $\gamma \mathrm{H} 2 \mathrm{AX}$-positive cells, the $\gamma \mathrm{H} 2 \mathrm{AX}$-staining pattern in scid retinas was imprecise (Supplementary Figure 2). Some cells in scid retinas presented diffuse nuclear staining, whereas a reduced proportion had nuclear foci, which were, however, less than those of wild type, thus suggesting that the NHEJ repair process is disturbed in this animal. The retinas from scid mouse had a higher density of TUNEL-positive nuclei than the corresponding wild-type retinas (Figures $5 \mathrm{e}-\mathrm{g}$ ), which correlated well with our previous ex vivo findings.

In addition to our observations with TUNEL as a marker of programmed cell death, the retinas exposed to NU7026 and those from the scid mouse had increased levels of activated caspase-3 (Figure 6), one of the main executors of apoptotic cell death in the developing nervous system. ${ }^{2,4,30}$ Accordingly, the increase in TUNEL-positive nuclei in the presence of the DNA-PK inhibitor was prevented by the general caspase inhibitor Boc-D-fmk (Figure 6d). Both these ex vivo and in vivo results support the involvement of DNA-PK, and likely of the NHEJ repair pathway, in regulating the correct levels of cell death in the developing retina. Hence, we further analyzed the impact of DNA-PK activity on other ongoing cellular processes.

Ex vivo inhibition of DNA-PK selectively affects neuronal number in the E14.5 retina. E14.5 retinas mostly contain proliferating neuroepithelial cells that can be identified by PCNA immunodetection, through the incorporation of BrdU, or by $\mathrm{pH} 3$ immunodetection when they undergo mitosis (Supplementary Figure 3). However, none of these markers were significantly affected when retinas were exposed to the 

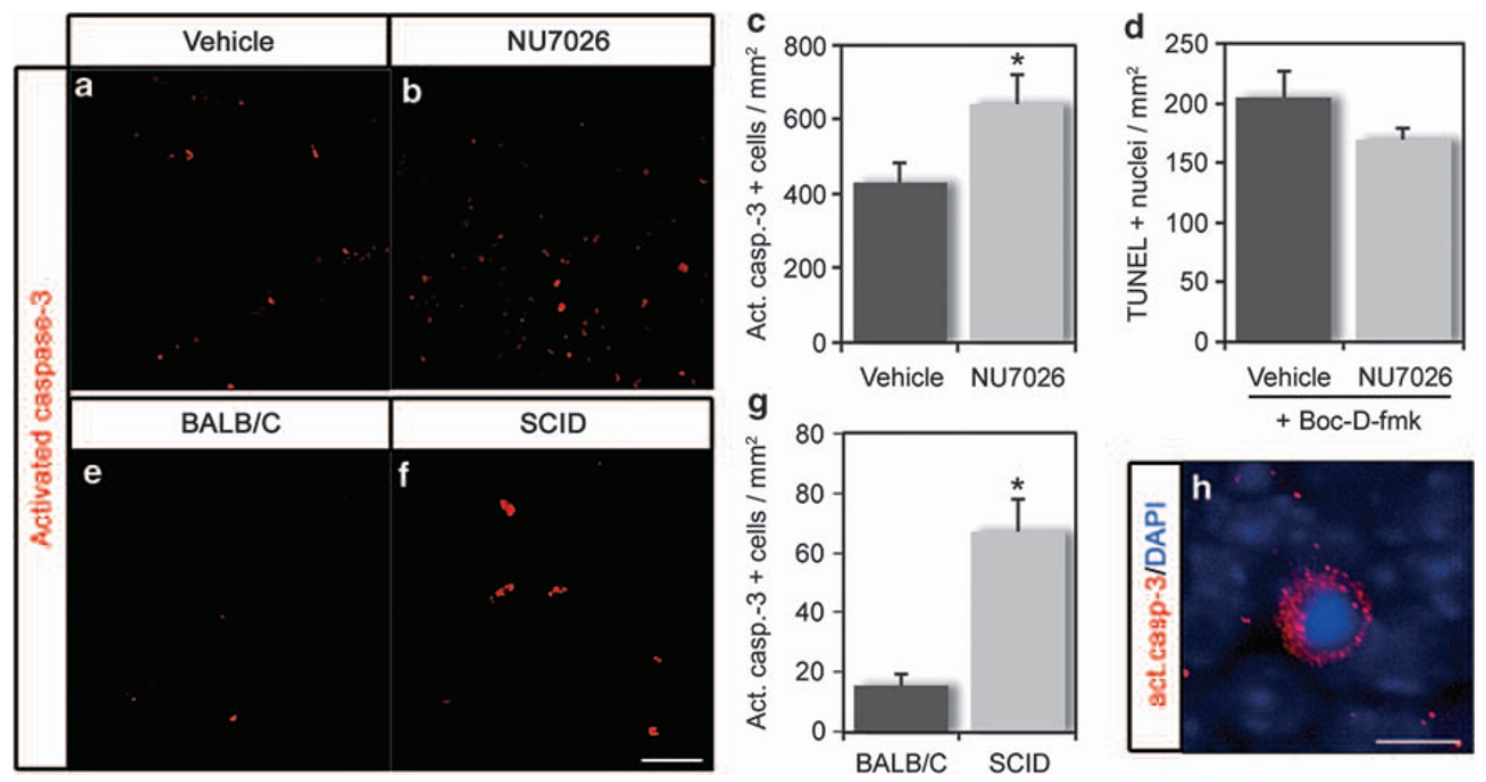

Figure 6 DNA-PK inhibition increases caspase-dependent cell death ex vivo and in vivo. E14.5 retinas cultured with the indicated compounds for $6 \mathrm{~h}$ (a-d) or freshly dissected E14.5 retinas from wild-type (BALB/c) and scid embryos (e-g) were flat mounted and processed for activated caspase-3 immunostaining (a-c, e- $\mathbf{g}$ and $\mathbf{h})$ or for TUNEL (d). Positive cells for each staining were scored in the whole retina and normalized per area. Graphs illustrate the mean \pm S.E.M. of at least seven individual retinas cultured in three independent experiments ( $\mathbf{c}$ and $\mathbf{d})$ or four individual retinas dissected from embryos with the indicated genotypes $(\mathbf{g})$. Panel $\mathbf{h}$ shows a higher magnification detail of the typical staining for activated caspase-3 (red) and the corresponding nuclear counterstain with DAPI (blue). ${ }^{*} P<0.05$ with respect to the corresponding controls. Scale bar, $40 \mu \mathrm{M}$ in $\mathbf{a}, \mathbf{b}, \mathbf{e}$ and $\mathbf{f}$, and $10 \mu \mathrm{M}$ in $\mathbf{h}$

DNA-PK inhibitor NU7026 (Supplementary Figure 3). Neurons, mainly RGCs, are actively generated at E14.5 and they are affected by the early phase of programmed cell death. ${ }^{18,19}$ The population of neurons identified by $\beta$ III tubulin immunostaining was significantly reduced by NU7026 (Figures 7a and b). Additional neuronal markers were used in immunoblots. The expression of Islet was also significantly reduced after DNA-PK inhibition (Figures 7d and e). Brn3a levels were also reduced to a similar extent, although the variability limited the significance of this observation. Interestingly, the general caspase inhibitor Boc-D-fmk prevented the loss of these neuronal markers in all cases (Figures 7c, d and f).

Contrary to our observations in cultured retinas, we did not detect any reduction in these neuronal markers in the retinas from scid mice (Figures $7 \mathrm{~g}, \mathrm{~h}$ and $\mathrm{i}$ ), possibly because of compensatory changes. This observation, which may lead to the underestimation of the real impact of the generation and repair of DSBs during neurogenesis, encouraged us to carry out a more detailed characterization of the dying cells observed ex vivo and in vivo after interference with DNA-PK.

Inhibition of ex vivo and in vivo deficiency of DNA-PK induced neuronal cell death in the E14.5 retina. To establish a direct relationship between the reduced number of neurons and the increase in programmed cell death, the density of Islet-positive neurons stained for apoptotic markers was assessed in both NU7026-treated and scid mouse retinas (Figure 8). In agreement with our earlier results (Figure $5 \mathrm{~d}$ ), the density of TUNEL-positive, Isletpositive nuclei increased in cultured wild-type E14.5 retinas after DNA-PK inhibition, but not after the inhibition of ATM
(Figures $8 a-d$ ). When activated caspase 3 was used as an alternative apoptotic marker, no significant differences were observed (data not shown), perhaps because of the small number of activated caspase 3-positive cells present in the retina (fewer than the cells identified by TUNEL: see Figures $5 \mathrm{~d}$ and $\mathrm{g}$ for TUNEL, and Figures $6 \mathrm{c}$ and $\mathrm{g}$ for activated caspase 3). However, an alternative method to visualize cells with general caspase activity again showed increased numbers of Islet-positive, caspase-active cells in the presence of NU7026 (Figures $8 \mathrm{e}-\mathrm{g}$ ). Through this approach, we also found an increase in the numbers of apoptotic Islet-positive young neurons in scid mouse retinas with respect to the corresponding wild type (Figures 8h-m). This increase was even greater when cell death was determined by TUNEL. Hence, our results indicate that young neurons at early stages of retinal development require correct DNA-PK activity for survival.

\section{Discussion}

Our results show that, under physiological conditions, the embryonic mouse neuroretina expresses several markers that reveal the existence of DSBs, as well as of active DNA repair. This expression overlaps with developmental processes, namely, neuroepithelial cell proliferation, neuron generation and the early phase of programmed cell death. Pharmacological inhibition of intrinsic DNA-PK activity with NU7026 in E14.5 neuroretina organotypic cultures, in the absence of any additional treatment to induce DNA damage, increased caspase-dependent cell death and selectively reduced the population of young neurons. Although the initial observation was confirmed in the embryonic retina of scid mice that lack DNA-PK activity, no 

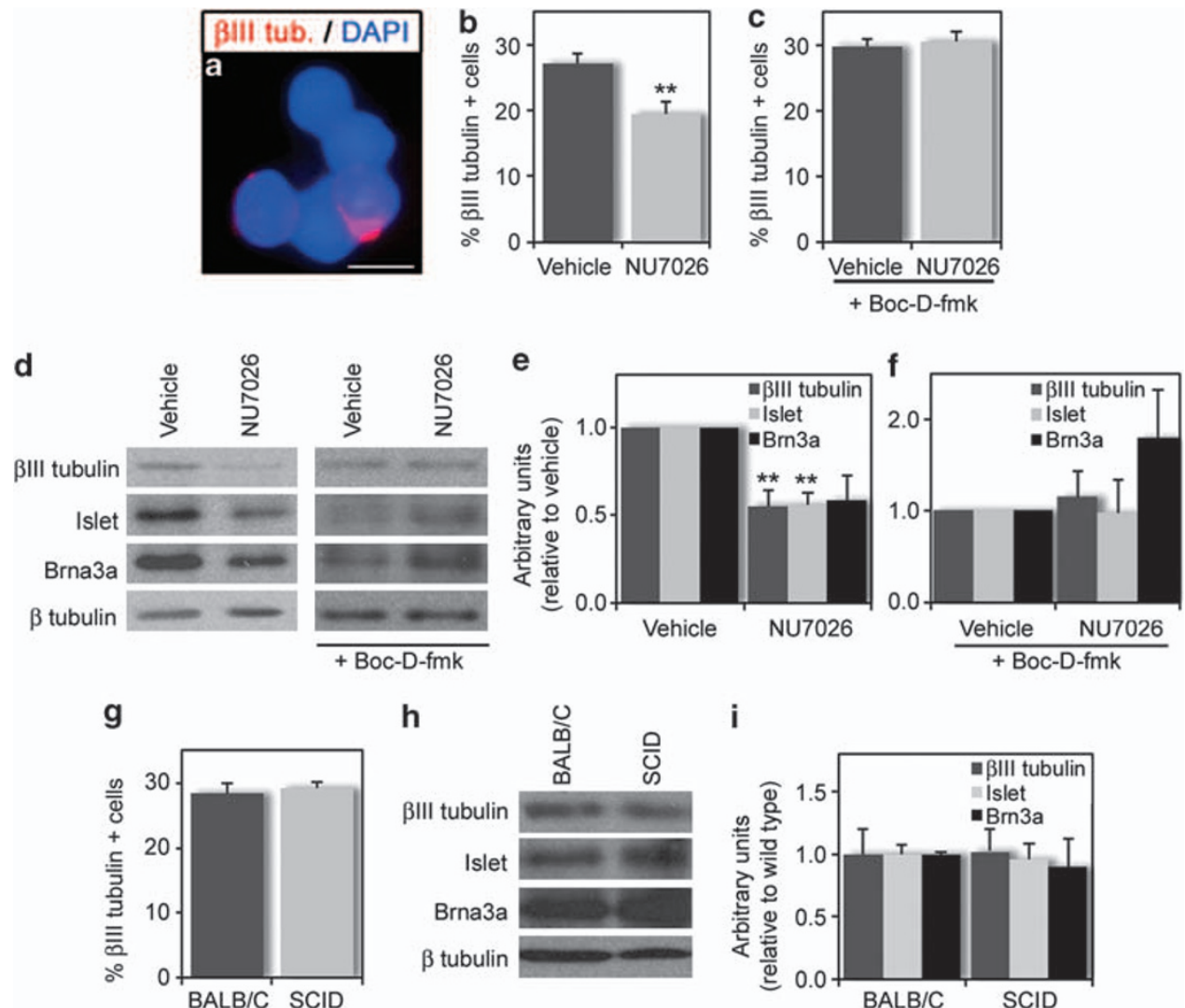

Figure 7 Inhibition of DNA-PK selectively decreases neuronal markers ex vivo. E14.5 retinas cultured with indicated compounds for $6 \mathrm{~h}(\mathrm{a}-\mathrm{f})$ or freshly dissected E14.5 retinas from wild-type (BALB/c) and scid embryos ( $\mathbf{g}-\mathbf{i})$ were dissociated into single cell suspensions and immunostained with $\beta$ III tubulin (red in $\mathbf{a}$; $\mathbf{a}-\mathbf{c}$ and $\mathbf{g}$ ). Positive cells were scored in at least 10 fields with $\mathbf{a} \times 40$ objective. Graphs $(\mathbf{b}, \mathbf{c}$ and $\mathbf{g})$ illustrate the mean \pm S.E.M. of the percentage of stained cells in at least six individual retinas. Total protein extracts of either cultured ( $\mathbf{d}-\mathbf{f}$ ) or freshly dissected retinas ( $\mathbf{h}$ and $\mathbf{i})$ were blotted against $\beta$ III tubulin, Islet, Brn3a and $\beta$ tubulin ( $\mathbf{d}$ and $\mathbf{h}$ ). Graphs $\mathbf{e}, \mathbf{f}$ and $\mathbf{i}$ represent the quantification of similar blots to the ones shown in $\mathbf{d}$ and $\mathbf{h}$ and illustrate the mean \pm S.E.M. of four independent experiments (after culture) or of individual retinas (in vivo analysis). ${ }^{\star *} P<0.01$, with respect to the corresponding controls. Scale bar in $\mathbf{a}, 10 \mu \mathrm{m}$

reduction in neuronal markers was found in vivo. However, an increased number of Islet-positive neurons double labeled with apoptotic markers were found in both NU7026-treated and scid mouse retinas, supporting the requirement of intrinsic DNA-PK activity for the survival of recently differentiated neurons, likely RGCs.

We previously used retinal organotypic cultures to characterize an early phase of programmed cell death in the embryonic chick and mouse retina, which was further corroborated in vivo. ${ }^{20-22,31}$ This process had been overlooked because of the high plasticity and rapid pace of early development. Here, we again used short-term pharmacological treatments in organotypic cultures, a type of culture that maintains a physiological environment and reproduces the early developmental processes fairly well, to establish the relationship between DSB repair, cell death and the affected cell types, which are essential aspects that may be partially masked by redundancy and compensatory changes in knockout animals. In our study, E14.5 retinal organotypic cultures responded to the genotoxic stimulus of etoposide in just $30 \mathrm{~min}$, by forming a large number of $\gamma \mathrm{H} 2 \mathrm{AX}$-positive nuclear foci that disappeared slowly on etoposide removal. Furthermore, this treatment upregulated several substrates of ATM, ATR and DNA-PK that participate in DSB repair and cell cycle progression. These substrates were selectively downregulated in the presence of pharmacological inhibitors, showing the ability of the developing retina to respond to DNA damage ex vivo.

We took advantage of the fact that several markers of an active DNA repair process were naturally present in the E14.5 mouse retina to establish the short-term consequences of interfering with the physiologically activated DNA repair process, without any additional extrinsic stimuli. Selective inhibition of DNA-PK, but not of ATM, increased caspasedependent cell death, an observation that correlates well with the phenotype of mutant mice. ${ }^{16,29,32}$ Further, interference with DNA-PK reduced the number of young neurons, without producing a clear effect on proliferating cells, and this effect was reverted by a pan-caspase inhibitor. DNA-PK inhibition directly affected neuronal survival. Indeed, the number of Islet-positive neurons showing apoptotic markers increased in the presence of the DNA-PK inhibitor, but not in the presence of an ATM inhibitor, supporting a specific role for DNA-PK in neuronal survival at this particular developmental stage. The lack of response of retinal neurons to ATM inhibition was unexpected. ATM has been described to be involved in neuronal apoptosis at later stages. ${ }^{33}$ The role of ATM in retinal neurogenesis deserves future studies. 

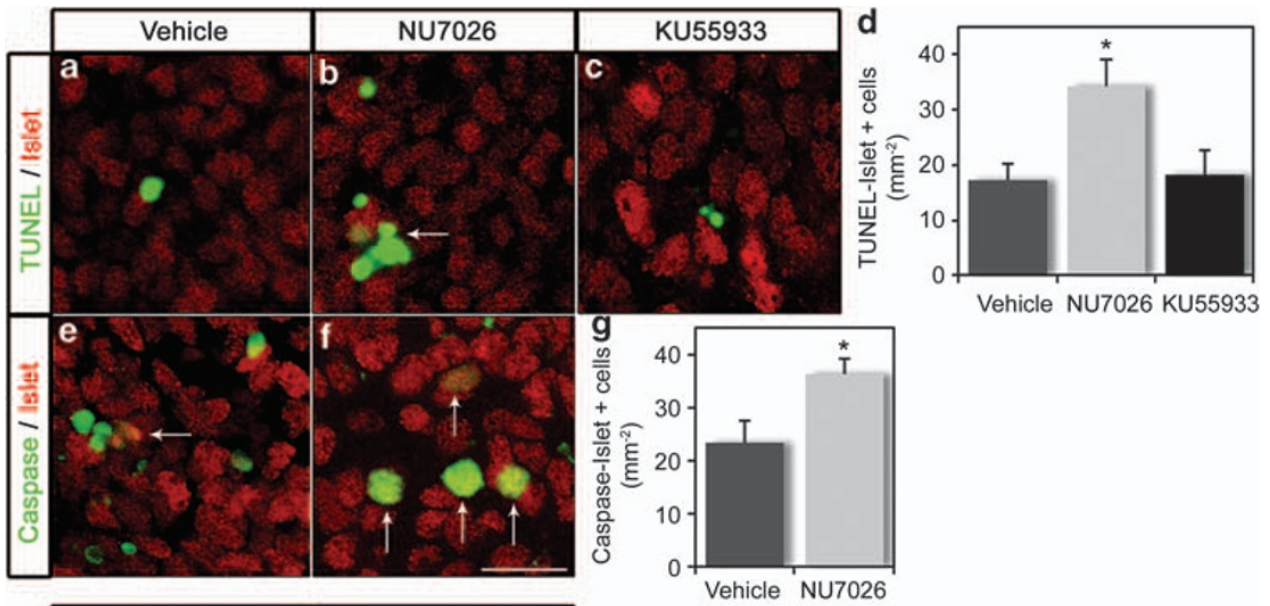

Vehicle NU7026 KU55933
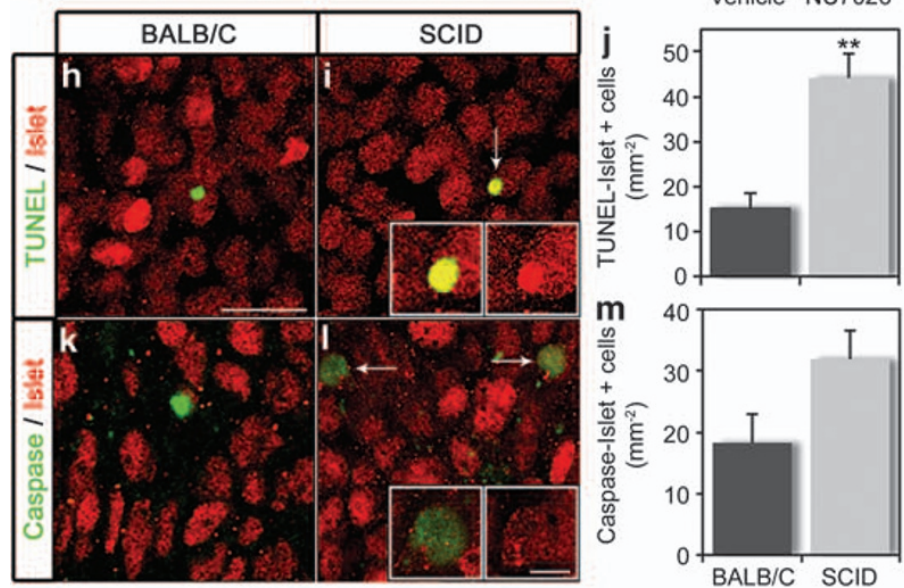

Figure 8 DNA-PK inhibition induces neuronal death ex vivo and in vivo. E14.5 retinas cultured for $6 \mathrm{~h}$ in the presence of indicated compounds (a-g) or freshly dissected E14.5 retinas from wild-type (BALB/c) and scid embryos (h-m) were processed for Islet immunostaining (red), combined with TUNEL (green in $\mathbf{a}, \mathbf{b}, \mathbf{c}, \mathbf{h}$ and i) or caspase marker (green in $\mathbf{e}, \mathbf{f}, \mathbf{k}$ and $\mathbf{I}$ ). Islet expressing neurons positive for TUNEL or for activated caspases (indicated with arrows in $\mathbf{b}, \mathbf{e}, \mathbf{f}, \mathbf{i}$ and $\mathbf{I}$ and shown at a higher magnification in insets in $\mathbf{i}$ and $\mathbf{I}$ ) were scored in the whole retina and normalized for each area. The graphs $(\mathbf{d}, \mathbf{g}, \mathbf{j}$ and $\mathbf{m})$ illustrate the mean \pm S.E.M. of at least four individual retinas. ${ }^{\star} P<0.05,{ }^{\star} P<0.01$ with respect to the corresponding controls. Scale bar, $20 \mu \mathrm{m}$ in $\mathbf{a}, \mathbf{b}, \mathbf{c}, \mathbf{e}, \mathbf{f}, \mathbf{h}, \mathbf{i}, \mathbf{k}$ and $\mathbf{I}, 5 \mu \mathrm{m}$ in the insets in $\mathbf{i}$ and $\mathbf{I}$

The selective involvement of the DSB repair pathways in neural development is also evident in genetically modified animals. For instance, HR deficiency caused by the deletion of Brca1 or Xrcc2 genes provokes embryonic lethality in mice because of increased apoptosis and decreased proliferation. Several regions of the nervous system are affected in these animal models, and while Brca1 knockout mice develop exencephaly and spina bifida, ${ }^{9}$ the loss of $X r c c 2$ affects the forebrain and hindbrain. ${ }^{7,10}$ Xrcc4 and LigIV are involved in NHEJ and their absence in mice leads to death at about E14.5 because of large-scale apoptosis affecting early postmitotic neurons. ${ }^{5,7,8}$ Therefore, although HR and NHEJ repair pathways are able to cooperate in proliferating systems, in the developing nervous system they seem to function selectively and separately in neural cells depending on their developmental stage, an observation that concurs with our ex vivo results.

The physiological relevance of our findings has been verified in the E14.5 retina from scid mice. Most of the phenotypes found ex vivo in the retinas treated with NU7026 were also observed in this mouse model, particularly the caspase-dependent cell death affecting young neurons. Interestingly and supporting our combined approach, retinas treated with NU7026 for only $6 \mathrm{~h}$ showed a downregulation of neuronal markers coincident with the increase in neuronal death, which we favor as the primary DNA-PK inhibition phenotype. This reduction in neuronal markers was not clear in the retina of scid embryos, probably because of compensatory effects.

Several key questions that remain pending are related to DSB generation. The accumulation of DSBs may be the result of DNA replication, transcription or oxidative metabolism, as postulated to explain the impact of deficient DSB repair in development. ${ }^{11,12,32}$ However, these alternatives do not explain the selectivity of the tissues and cells affected, the immune and nervous systems $\mathrm{s}^{2,6}$ and, more specifically, the effects on young neurons in both knockout animals and through our pharmacological approach..$^{5,7,8,11}$ One might speculate that in the central nervous system, as in the immune system, DSBs underlie genomic rearrangements that trigger apoptosis if not adequately repaired. Events similar to somatic recombination have not been shown in the central nervous system. Nevertheless, LINE-1-mediated retrotransposition, an additional source of DSBs that also activates the DNA damage response, seems to be associated with neural differentiation in both rat and human neural progenitors, giving 
rise to somatic mosaicism. ${ }^{34,35}$ Intriguingly, the human hippocampus and other brain regions contain 1000 times more endogenous copies of LINE-1 than the heart or the liver. $^{36}$ LINE-1-mediated retrotransposition during neurogenesis and the consequent error-prone NHEJ repair process may underlie the early phase of neural cell death, which is magnified in DSB repair-deficient mice, as well as in our present observations.

Short-term ex vivo pharmacological approaches may serve to further analyze the role of alternative DSB repair pathways independently. More important, they could be used to uncover phenotypes that are not always evident when embryos are analyzed. In addition, they could be combined with more detailed analyses of knockout mice available to provide further evidence of the relationships between DSB generation and neural development.

\section{Materials and Methods}

Mice. C57BL/6J, BALB/c and Prkdc scid/Prkdc scid mice were reared in local facilities under a 12-h light/12-h dark cycle at $20^{\circ} \mathrm{C}$. Mice were mated and the morning of appearance of a vaginal plug was designated E0.5. Mouse embryos were collected from killed pregnant females, whereas other experiments were carried out on postnatal mice at day 2. Unless indicated, all experiments were carried out on C57BI/6 embryos and postnatal animals. All experiments were approved by the local ethics committee for animal experiments and they were carried out in accordance with the European Union guidelines.

Genotyping of embryos carrying the Prkdcscid mutation was performed as previously described. ${ }^{37}$

Neuroretina organotypic culture. Eyes were collected from E14.5 embryos and the neuroretina was dissected free of surrounding tissues. Isolated neuroretinas were plated in chemically defined DMEM/F12 (GibcoBRL, New York, NY, USA) with N2 supplement (Sigma, St. Louis, MI, USA) and cultured for $6 \mathrm{~h}$ at $37^{\circ} \mathrm{C}$ in $5 \% \mathrm{CO}_{2}$. Where indicated, etoposide (10 $\mu \mathrm{M}$, Sigma), NU7026 (200 nM, Calbiochem, Darmstadt, Germany), KU99533 (13 nM, Tocris Bioscience, Bristol, UK), Boc-D-fmk ( $38 \mu \mathrm{M}$, Calbiochem) or BrdU ( $5 \mu \mathrm{M}$, Sigma) were added to the medium. After culture, the retinas were washed twice with phosphate-buffered saline (PBS) and processed as required.

Detection of apoptosis. TUNEL of fragmented DNA was performed using FITC-dUTP on E13.5 to P2 whole-mount retinas as described previously ${ }^{21}$ and according to the manufacturer's instructions (Apoptosis Detection System; Promega, Madison, WI, USA). Briefly, freshly dissected or cultured retinas were flat mounted onto nitrocellulose membranes and fixed overnight in $4 \%$ paraformaldehyde $(\mathrm{w} / \mathrm{v})$ in $0.1 \mathrm{M}$ phosphate buffer $(\mathrm{pH} 7.4)$ at $4^{\circ} \mathrm{C}$. Fixed neuroretinas were permeated for $2 \mathrm{~h}$ with $1-4 \%$ Triton X-100 (w/v; Fluka, Buchs, Switzerland), depending on the developmental stage, mildly digested for $10 \mathrm{~min}$ at $37^{\circ} \mathrm{C}$ with proteinase $\mathrm{K}(20 \mu \mathrm{g} / \mathrm{ml}$, Promega) and fixed again with $4 \%$ paraformaldehyde $(\mathrm{w} / \mathrm{v})$ in $0.1 \mathrm{M}$ phosphate buffer $(\mathrm{pH} 7.4)$ for $20 \mathrm{~min}$ at room temperature (RT). After several washes with PBS, the retinas were stained by TUNEL, mounted with Vectashield mounting medium (Vector Laboratories, Burlingame, CA, USA) and analyzed by confocal microscopy (Leica TCS-SP2AOBS, Leica Microsystems GmbH, Wetzlar, Germany). The density of the apoptotic bodies was determined by counting TUNEL-positive nuclei and nuclear fragments throughout the whole retina with a $\times 40$ objective on a Zeiss fluorescence microscope (Zeiss Axioplan, Oberkochen, Germany).

For Annexin-V staining (TACS Annexin V-Biotin Apoptosis Detection Kit; Trevigen, Gaithersburg, MD, USA), freshly dissected E14.5 retinas were flat mounted onto nitrocellulose membranes and incubated for $30 \mathrm{~min}$ at $37^{\circ} \mathrm{C}$ and $5 \%$ $\mathrm{CO}_{2}$, with $4 \%$ Annexin-V-biotin and $5 \%$ binding buffer in culture medium. After several washes with PBS, the retinas were fixed for $3 \mathrm{~h}$ with $4 \%$ paraformaldehyde at RT and permeated as described above. The retinas were further incubated for $1 \mathrm{~h}$ with Alexa-488 conjugated to avidin (Molecular Probes, Invitrogen, Carlsbad, CA, USA), washed with PBS, mounted with Vectashield mounting medium and analyzed by confocal microscopy.
In situ caspase activity labeling was carried out in E14.5 retinas using the CaspACE FITC-VAD-fmk Marker (Promega). A volume of $10 \mu \mathrm{M}$ of FITC-VAD-fmk was directly added to the organotypic retinal cultures during the last hour of incubation. Retinas were then washed several times with PBS, flat mounted onto nitrocellulose membranes and fixed for $3 \mathrm{~h}$ at RT with $4 \%$ paraformaldehyde. Fixed neuroretinas were mounted with Vectashield mounting medium and analyzed by confocal microscopy. Cells stained for activated caspases were scored throughout the whole retina with a $\times 100$ objective on a Zeiss Axioplan fluorescence microscope.

Immunostaining of whole-mount retinas. Freshly dissected or cultured retinas were flat mounted, fixed and permeated as above. The retinas were subsequently incubated overnight at $4^{\circ} \mathrm{C}$ with primary antibodies against activated caspase-3 (1/100, Cell Signaling Technology, Danvers, MA, USA); $\gamma$ H2AX (1/1000, Abcam, Cambridge, UK); pH3 (Ser10, 1/100, Millipore, Billerica, MA, USA); or Islet-1 homeobox (clone 40.2D6, 1/200, Developmental Studies Hybridoma Bank, lowa, IN, USA). After several washes with PBS, the retinas were further incubated for $1 \mathrm{~h}$ at RT with Alexa-488, Alexa-568 or Texas Red conjugated secondary antibodies (Molecular Probes). They were then mounted with Vectashield mounting medium and analyzed by confocal microscopy. Positively stained cells were scored with a $\times 40$ objective on a Zeiss Axioplan fluorescence microscope, except for TUNEL-, active caspase-3- or FITC-VAD-fmk-positive cells double-stained with Islet, which were quantified under $\mathrm{a} \times 100$ objective.

Immunostaining of dissociated cells. Freshly dissected or cultured retinas were mildly digested for $10 \mathrm{~min}$ at $37^{\circ} \mathrm{C}$ with Accutase (Sigma). Dissociated live cells were then fixed with $4 \%$ paraformaldehyde (w/v) in $0.1 \mathrm{M}$ phosphate buffer (pH 7.4) for $1 \mathrm{~h}$ at RT and washed three times with BSA in PBS $(30 \mathrm{mg} / \mathrm{ml}$, Roche, Mannheim, Germany). Cells corresponding to half of a retina were cytocentrifuged on microscope slides pretreated with poly-L-lysine (Sigma). The cells were then permeated with $0.2 \%(\mathrm{w} / \mathrm{V})$ Triton $\mathrm{X}-100$ for $1 \mathrm{~h}$ at RT and incubated overnight at $4{ }^{\circ} \mathrm{C}$ with primary antibodies against $\gamma \mathrm{H} 2 \mathrm{AX}$ (1/1000); pATM (Ser1981, 1/1000, Millipore); DNA-PK (1/200, Cell Signaling Technology); $\beta$ III tubulin (1/1000, TUJ-1, Covance, Paris, France); PCNA (1/250, Delta Biolabs, Gilroy, CA, USA); pH3 (Ser10, 1/100, Millipore); or BrdU (1/1000, G3G4, Developmental Studies Hybridoma Bank). After being washed several times with PBS, the cells were incubated with Alexa-488 or Texas Red conjugated secondary antibodies for $1 \mathrm{~h}$ at RT. They were then mounted with Vectashield mounting medium. Positive cells were scored counting at least 10 fields under a $\times 40$ objective and photographed using a Zeiss Axioplan fluorescence microscope.

Western blotting. Individual retinas were lysed in a buffer containing $50 \mathrm{mM}$ Tris-HCl (pH 6.8), 10\% (v/v) glycerol, 2\% (w/v) SDS, $10 \mathrm{mM} \mathrm{DTT}$ and $0.005 \%$ (w/v) bromophenol blue. The total protein from each retina was resolved on a $12 \%$ SDS-PAGE gel and proteins were transferred to PVDF membranes (Bio-Rad, Hercules, CA, USA). The membranes were then blocked for $1 \mathrm{~h}$ in TBS- or PBS-Tween 20 $(0.1 \% \mathrm{w} / \mathrm{v})$ containing BSA $(3 \% \mathrm{w} / \mathrm{v})$ and probed with antibodies against $\gamma \mathrm{H} 2 \mathrm{AX}$ (1/1000); H2AX (1/5000, Abcam); pChk1 (Ser345); Chk1; pAkt (Ser473); Akt (all from Cell Signaling Technology and used at a 1/1000 dilution); p21 (1/100, Santa Cruz Biotechnology, Santa Cruz, CA, USA); p53 (1/500, Calbiochem); pH3 (Ser10, 1/1000, Millipore); H3 (1/1000, Santa Cruz Biotechnology); $\beta$ III tubulin (1/5000, Covance); Islet1-1 homeodomain (1/200, Developmental Studies Hybridoma Bank); Brn3a (1/100, Millipore); and $\beta$ tubulin (1/10000, Sigma). Antibodies were detected with appropriate horseradish peroxidase-labeled secondary antibodies (Pierce, Rockford, IL, USA) and visualized with the Super Signal West Pico chemiluminescent substrate (Pierce).

RT-PCR analysis. Total RNA was extracted from freshly dissected retinas using Trizol reagent (Invitrogen) and digested with DNase I (Invitrogen). Reverse transcription was carried out on $1 \mu \mathrm{g}$ of RNA using Oligo(dT) ${ }^{18-20}$ and the Superscript III enzyme (Invitrogen), according to the manufacturer's instructions. Semiquantitative RT-PCR was carried out using Taq polymerase (Invitrogen) under the following conditions: an initial denaturation step at $94^{\circ} \mathrm{C}$ for $1 \mathrm{~min}$, followed by $30-35$ cycles of denaturation at $94^{\circ} \mathrm{C}$ for $30 \mathrm{~s}$, annealing at $58^{\circ} \mathrm{C}$ for $45 \mathrm{~s}$ and extension at $72^{\circ} \mathrm{C}$ for $45 \mathrm{~s}$; and a final elongation at $72^{\circ} \mathrm{C}$ for $1 \mathrm{~min}$. The primer sequences used were the following: H2AX: forward, $5^{\prime}$-GTCCTGCCC AACATCCAG-3'; reverse, 5'-TGGCTCAGCTCTTTCTGTGA-3'; p53: forward, 5'-AGAGACCGCCGTACAGAAGA-3'; reverse, 5'-GCATGGGCATCCTTTAACTC-3'; ATM: forward, 5'-CTGGATCACCCCCATCATAC-3'; reverse, 5'-ACTGAGAGG 
CGTCCATGTTT-3'; DNA-PK: forward, 5'-GAGGCCATGATGAAAAGGAA-3'; reverse, 5'-CGCTTTGGGGTCACTGTTAT-3'; Ku70: forward, 5'-CCAAAAAGCG AGTTCTGTCC-3'; reverse, 5'-TGACGTGTCCCGTAAGTAG-3'; Lig IV: forward, 5'-ATGACCTGGGCTTGAAATTG-3'; reverse, 5'-TCGTGCCACTCTTTGTCATC-3'; and s16: forward, 5'-TTCTGGGCAAGGAGCATT-3'; reverse, 5'-GATGGAC TGTCGGATGGCA- $3^{\prime}$. The RT-PCR products were visualized by ethidium bromide staining $(1 \mu \mathrm{g} / \mathrm{ml})$ on a $1.5 \%$ agarose gel and the identity of the products was confirmed by DNA sequencing.

\section{Conflict of interest}

The authors declare no conflict of interest.

Acknowledgements. This work was supported by the Ministerio de Ciencia e Innovación, Spain (Grant SAF2007-66175 to EJdIR). JB is an FPI Fellow (Ministerio de Ciencia e Innovación). We thank Dr. Violeta Gómez-Vicente for critical reading of the paper, and Professor Flora de Pablo for continuous encouragement and ideas. We thank Maite Seisdedos, Noemí Alvarez, Ana Robles and the staff of the CIB animal house for technical support.

1. Yeo W, Gautier J. Early neural cell death: dying to become neurons. Dev Biol 2004; 274 233-244.

2. Boya P, de la Rosa EJ. Cell death in early neural life. Birth Defects Res C Embryo Today 2005; 75: 281-293.

3. Buss RR, Sun W, Oppenheim RW. Adaptive roles of programmed cell death during nervous system development. Annu Rev Neurosci 2006; 29: 1-35.

4. Kuida K, Zheng TS, Na S, Kuan C, Yang D, Karasuyama $\mathrm{H}$ et al. Decreased apoptosis in the brain and premature lethality in CPP32-deficient mice. Nature 1996; 384: 368-372.

5. Gao Y, Sun Y, Frank KM, Dikkes P, Fujiwara Y, Seidl KJ et al. A critical role for DNA endjoining proteins in both lymphogenesis and neurogenesis. Cell 1998; 95: 891-902.

6. Chun J, Schatz DG. Rearranging views on neurogenesis: neuronal death in the absence of DNA end-joining proteins. Neuron 1999; 22: 7-10.

7. Orii KE, Lee Y, Kondo N, McKinnon PJ. Selective utilization of nonhomologous end-joining and homologous recombination DNA repair pathways during nervous system development. Proc Natl Acad Sci USA 2006; 103: 10017-10022.

8. Frank KM, Sekiguchi JM, Seidl KJ, Swat W, Rathbun GA, Cheng HL et al. Late embryonic lethality and impaired V(D)J recombination in mice lacking DNA ligase IV. Nature 1998; 396: 173-177.

9. Gowen LC, Johnson BL, Latour AM, Sulik KK, Koller BH. Brca1 deficiency results in early embryonic lethality characterized by neuroepithelial abnormalities. Nat Genet 1996; 12: 191-194.

10. Deans B, Griffin CS, Maconochie M, Thacker J. Xrcc2 is required for genetic stability, embryonic neurogenesis and viability in mice. EMBO J 2000; 19: 6675-6685.

11. Biton S, Barzilai A, Shiloh Y. The neurological phenotype of ataxia-telangiectasia: solving a persistent puzzle. DNA Repair (Amst) 2008; 7: 1028-1038.

12. McKinnon PJ. DNA repair deficiency and neurological disease. Nat Rev Neurosci 2009; 10 100-112.

13. Weterings $E$, Chen DJ. The endless tale of non-homologous end-joining. Cell Res 2008; 18: $114-124$.

14. Fernandez-Capetillo $O$, Lee $A$, Nussenzweig M, Nussenzweig A. H2AX: the histone guardian of the genome. DNA Repair (Amst) 2004; 3: 959-967.

15. Shiotani B, Zou L. Single-stranded DNA orchestrates an ATM-to-ATR switch at DNA breaks. Mol Cell 2009; 33: 547-558.
16. Murga M, Bunting S, Montana MF, Soria R, Mulero F, Canamero M etal. A mouse model of ATR-Seckel shows embryonic replicative stress and accelerated aging. Nat Genet 2009; 41: $891-898$.

17. Dar I, Biton S, Shiloh $Y$, Barzilai A. Analysis of the ataxia telangiectasia mutatedmediated DNA damage response in murine cerebellar neurons. J Neurosci 2006; 26: 7767-7774.

18. Cepko CL, Austin CP, Yang X, Alexiades M, Ezzeddine D. Cell fate determination in the vertebrate retina. Proc Natl Acad Sci USA 1996; 93: 589-595.

19. Valenciano Al, Boya P, de la Rosa EJ. Early neural cell death: numbers and cues from the developing neuroretina. Int J Dev Biol 2009; 53: 1515-1528.

20. de la Rosa EJ, Diaz B, de Pablo F. Organoculture of the chick embryonic neuroretina. Curr Top Dev Biol 1998; 36: 133-144.

21. Diaz B, Pimentel B, de Pablo F, de La Rosa EJ. Apoptotic cell death of proliferating neuroepithelial cells in the embryonic retina is prevented by insulin. Eur J Neurosci 1999; 11: $1624-1632$.

22. Valenciano Al, Corrochano S, de Pablo F, de la Villa P, de la Rosa EJ. Proinsulin/insulin is synthesized locally and prevents caspase- and cathepsin-mediated cell death in the embryonic mouse retina. J Neurochem 2006; 99: 524-536.

23. Rogakou EP, Nieves-Neira W, Boon C, Pommier $Y$, Bonner WM. Initiation of DNA fragmentation during apoptosis induces phosphorylation of H2AX histone at serine 139. J Biol Chem 2000; 275: 9390-9395.

24. Rossi R, Lidonnici MR, Soza S, Biamonti G, Montecucco A. The dispersal of replication proteins after etoposide treatment requires the cooperation of Nbs1 with the ataxia telangiectasia Rad3-related/Chk1 pathway. Cancer Res 2006; 66: 1675-1683.

25. Tanaka T, Halicka HD, Traganos F, Seiter K, Darzynkiewicz Z. Induction of ATM activation, histone $\mathrm{H} 2 \mathrm{AX}$ phosphorylation and apoptosis by etoposide: relation to cell cycle phase. Cell Cycle 2007; 6: 371-376.

26. Abe T, Ishiai M, Hosono Y Yoshimura A, Tada S, Adachi N et al. KU70/80, DNA-PKcs, and Artemis are essential for the rapid induction of apoptosis after massive DSB formation. Cell Signal 2008; 20: 1978-1985.

27. Zaugg K, Su YW, Reilly PT, Moolani Y, Cheung CC, Hakem R et al. Cross-talk between Chk1 and Chk2 in double-mutant thymocytes. Proc Natl Acad Sci USA 2007; 104 3805-3810.

28. Wood A, Shilatifard A. Transcriptional blackjack with p21. Genes Dev 2006; 20: 643-647.

29. Vemuri MC, Schiller E, Naegele JR. Elevated DNA double strand breaks and apoptosis in the CNS of scid mutant mice. Cell Death Differ 2001; 8: 245-255.

30. Mayordomo R, Valenciano Al, de la Rosa EJ, Hallbook F. Generation of retinal ganglion cells is modulated by caspase-dependent programmed cell death. Eur J Neurosci 2003 18: $1744-1750$.

31. Mellen MA, de la Rosa EJ, Boya P. The autophagic machinery is necessary for removal of cell corpses from the developing retinal neuroepithelium. Cell Death Differ 2008; 15 1279-1290.

32. Narasimhaiah R, Tuchman A, Lin SL, Naegele JR. Oxidative damage and defective DNA repair is linked to apoptosis of migrating neurons and progenitors during cerebral cortex development in Ku70-deficient mice. Cereb Cortex 2005; 15: 696-707.

33. Frappart PO, McKinnon PJ. Mouse models of DNA double-strand break repair and neurological disease. DNA Repair (Amst) 2008; 7: 1051-1060.

34. Muotri AR, Chu VT, Marchetto MC, Deng W, Moran JV, Gage FH. Somatic mosaicism in neuronal precursor cells mediated by L1 retrotransposition. Nature 2005; 435: 903-910.

35. Gasior SL, Wakeman TP, Xu B, Deininger PL. The human LINE-1 retrotransposon creates DNA double-strand breaks. J Mol Biol 2006; 357: 1383-1393.

36. Coufal NG, Garcia-Perez JL, Peng GE, Yeo GW, Mu Y, Lovci MT et al. L1 retrotransposition in human neural progenitor cells. Nature 2009; 460: 1127-1131.

37. Maruyama C, Suemizu H, Tamamushi S, Kimoto S, Tamaoki N, Ohnishi Y. Genotyping the mouse severe combined immunodeficiency mutation using the polymerase chain reaction with confronting two-pair primers (PCR-CTPP). Exp Anim 2002; 51: 391-393.

\section{Supplementary Information accompanies the paper on Cell Death and Differentiation website (http://www.nature.com/cdd)}

